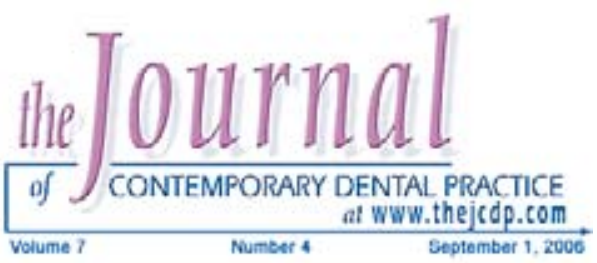

\title{
Prevalence, Intensity, and Correlation of Different TMJ Symptoms in Lebanese and Italian Subpopulations
}

\author{
Youssef S. Abou-Atme, DDS, MS; Khalid H. Zawawi, BDS, DSc;
}

Marcello Melis, DMD, RPharm

$\nabla$

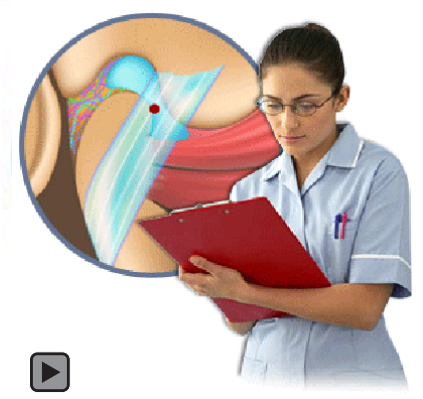

Abstract

Aim: The aim of this study was to compare self reported joint related temporomandibular disorder (TMD) symptoms in Lebanese and Italian dental and non-dental students and to detect any correlation between different symptoms.

Methods and Materials: A questionnaire was distributed in Sardinia (Italy) to dental and psychology students and in Lebanon to dental, physical therapy, and biology students to investigate the prevalence, intensity, and correlation of four temporomandibular joint (TMJ) symptoms.

Results: Prevalence of earache varied among the groups from $10.1 \%$ to $29.2 \%$, ear stuffiness from $22.5 \%$ to $30.8 \%$, TMJ pain from $13.2 \%$ to $21.2 \%$, and TMJ sounds from $18.4 \%$ to $46.2 \%$.

Discussion: Different prevalence and intensity of earache and TMJ sounds were found in the examined subpopulations diverse in cultural background and education. However, prevalence and intensity of ear stuffiness and TMJ pain were similar. Association between TMJ sounds and TMJ pain was detected in selected subpopulations, and correlation between one symptom on one side of the head with the same symptom on the contralateral side were noted suggesting most of these symptoms are bilateral.

Conclusion: The results of the study might be useful to anticipate the possible occurrence of associated symptoms or the same symptom on both sides of the head. Correlations with cultural background and education are difficult to establish.

Keywords: Temporomandibular disorder, TMD, temporomandibular joint, TMJ, epidemiology, TMJ sounds, TMJ pain, TMJ symptoms, earache, ear stuffiness

Citation: Abou-Atme YS, Zawawi KH, Melis M. Prevalence, Intensity, and Correlation of Different TMJ Symptoms in Lebanese and Italian Subpopulations. J Contemp Dent Pract 2006 September;(7)4:071-078.

(C) Seer Publishing 


\section{Introduction}

The prevalence of signs and symptoms of temporomandibular disorders (TMD) in the general population varies according to the different studies examined. The guidelines of the American Academy of Orofacial Pain estimates $40 \%$ to $75 \%$ of the population displays at least one sign of the disease and $33 \%$ of the population reports at least one symptom. ${ }^{1}$ Nonetheless, some signs are common in nonpatient populations. These include such signs as joint sounds and deviation of the mandible on mouth opening occurring in about $50 \%$ of the subjects, while other signs like limitation of mouth opening are rare occurring in about $5 \%$ of the subjects. ${ }^{1}$ High variability was reported by Carlsson $^{2}$ in a review of epidemiological studies, who described prevalence of TMD ranging from $6 \%$ to $93 \%$ when based on subjects' reports and from $0 \%$ to $93 \%$ when based on direct clinical evaluation. Treatment need for the pathology was less variable with most of the studies showing percentages ranging from $21 \%$ to $30 \%{ }^{2}$

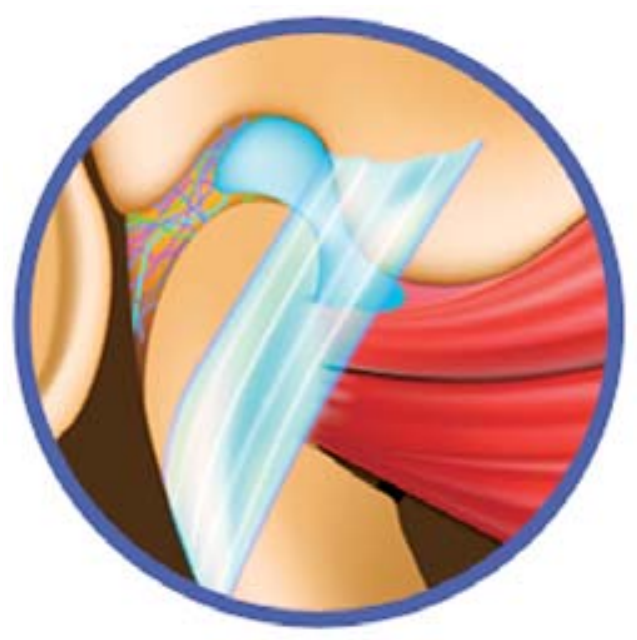

Frequent complaints from TMD patients are ear pain, ear stuffiness, hearing loss, and tinnitus; their prevalence is higher compared to control subjects without signs or symptoms of TMD, ${ }^{3-6}$ and this is probably the reason why more than $50 \%$ of TMD patients in private practice are seen or referred by otolaryngologists. ${ }^{7}$ About one third of the individuals affected by tinnitus reported an influence on the condition by jaw movements or pressure placed on the temporomandibular joint (TMJ). Diurnal bruxism and jaw fatigue seemed to be related to fluctuating tinnitus, vertigo, and hyperacusis. ${ }^{8,9}$
Joint sounds were found to be the most frequent symptoms reported by 219 Saudi Arabian subjects attending a dental clinic for routine dental treatment $(36 \%)^{10}$ and in an urban Swedish sample of 637 subjects (58\%). ${ }^{11}$ In an investigation by Elfving et al. ${ }^{12}$ the prevalence and type of different joint sounds were registered in 125 consecutive patients with suspected TMD and in 125 matched controls. The study reported joint sounds in $56 \%$ of the TMD patients and in $36 \%$ of the controls. The awareness of joint sounds was also higher among TMD patients as compared to controls ( $88 \%$ and $60 \%$, respectively).

Agerberg et al. ${ }^{13}$ studied symptoms of mandibular dysfunction and some general and oral conditions in a group of previous patients and in a randomly selected population sample. The most frequent symptoms of mandibular dysfunction found were TMJ sounds which appeared in $39 \%$ of the population sample and $79 \%$ of the previous patients, as well as pain on mouth opening, which occurred in $12 \%$ of the population and $42 \%$ of the previous patients.

Although studies reporting TMD symptoms of Arabic subjects show similar results to those of western populations, ${ }^{14}$ no study tried to compare TMJ symptoms in Arabic and western subjects, including controls. Therefore, the aim of this study was to compare self reported joint related TMD symptoms in Lebanese and Italian dental and non-dental students and to detect any correlation between different symptoms.

\section{Methods and Materials}

A TMJ symptom questionnaire was distributed to dental students at the University of Cagliari in Sardinia, Italy and the University of Saint Joseph in Lebanon.

The questionnaire was distributed to all but one dental student at the University of Cagliari (N1=114 out of 115 consisting of 60 males and 54 females with a mean age of 22.7 years). Age and gender matched psychology students (N2=114) of the same University also received the questionnaire.

The questionnaire was also distributed to all dental students at the University of Saint Joseph (N3=178; 117 males and 61 females, mean 
INSTRUCTIONS: Please rate the intensity of the following symptoms from 0 to 3: 0 for absence of the symptom, 1 for mild intensity, 2 for moderate intensity, and 3 for maximum intensity. Put an $X$ in the corresponding box.

\begin{tabular}{|l|l|l|l|l|}
\hline \multirow{2}{*}{ TMJ* pain } & & $\mathbf{0}$ & $\mathbf{1}$ & $\mathbf{2}$ \\
\hline \multirow{2}{*}{$\begin{array}{l}\text { TMJ* sounds on mouth opening and } \\
\text { closing }\end{array}$} & Right & & & 3 \\
\hline & Left & & & \\
\hline \multirow{2}{*}{ Earache } & Right & & & \\
\hline & Left & & & \\
\hline \multirow{2}{*}{ Ear Stuffiness } & Right & & & \\
\hline & Left & & & \\
\hline
\end{tabular}

- TMJ stands for Temporomandibular Joint. It is the joint allowing the opening of the mouth and is located just in front of the ears.

Figure 1. TMJ symptoms questionnaire.

age 20.7 years) as well as all physical therapy students (N4=52; 22 males and 30 females, mean age 20.3 years) and 72 biology students (N5=72; 14 males and 58 females, mean age 19.8 years) of the same University.

Using the questionnaire (Figure 1), subjects were asked to rate their right and left TMJ pain, TMJ sounds, earache, and ear stuffiness on a 0-3 numeric visual analog scale questionnaire $(0$ for absence of the symptom, 1 for mild intensity, 2 for moderate intensity, and 3 for maximum intensity).

\section{Statistical Analyses}

Prevalence of the symptoms in each subpopulation was calculated, and the difference between groups for the prevalence of each symptom was analyzed using the Chi-square $\left(\chi^{2}\right)$ test .

For every group, the mean of the intensity indicated by the subjects for each symptom (left and right side together) were calculated and compared. The difference between groups was first analyzed by analysis of variance (ANOVA). If a statistically significant difference was observed, the difference between the two groups was analyzed by pair wise multiple comparisons. The Tukey method was used to correct for type-I errors. The difference was considered significant for $p<0.05$. A Pearson correlation was performed to conduct analyses between symptoms. Statistical analyses were performed using the Statistical Package for the Social Sciences (SPSS Inc., Chicago, IL, USA).
Results

Prevalence of earache varied among the groups from $10.1 \%$ to $29.2 \%$, ear stuffiness from $22.5 \%$ to $30.8 \%$, TMJ pain from $13.2 \%$ to $21.2 \%$, and TMJ sounds from $18.4 \%$ to $46.2 \%$ (Table 1 , Figure 2).

A significant difference between groups was observed for earache and TMJ sounds, $\chi_{\mathrm{df}=4}^{2}=16.6$ and 15.4 , respectively, $p<0.01$. No difference was observed for ear stuffiness and TMJ pain, $\chi_{\mathrm{df}=4}^{2}=2.2$ and 2.9 , respectively, $\mathrm{p}>0.05$.

Figure 2 also shows a comparison between the groups for earache; Lebanese dental students were different from Italian dental students $(p=0.035)$, Lebanese biology students $(p<0.001)$, and Lebanese physical therapy students $(p=0.005)$. A comparison between the groups for TMJ sounds showed Italian psychology students were different from Italian dental students $(p=0.015)$ and Lebanese physical therapy students $(p<0.001)$; Lebanese physical therapy students were also different from Lebanese dental students $(p=0.011)$, and Lebanese biology students $(p=0.035)$.

ANOVA between the groups showed there was a significant difference between the groups for intensity of earache and TMJ sounds, $F_{d=4}=2.6$, $\mathrm{p}=0.038$ and $\mathrm{F}_{\mathrm{df}=4}=5.8, \mathrm{p}<0.001$, respectively. No significant difference was observed between the groups for intensity of ear stuffiness and TMJ pain, p>0.05 (Table 2, Figure 3). 
Table 1. Prevalence of TMD symptoms in the selected sub-populations.

\begin{tabular}{|l|c|c|c|c|}
\hline & Earache & Ear Stuffiness & TMJ Pain & TMJ Sounds \\
\hline Italian psychology students & $17.5 \%$ & $28.9 \%$ & $13.2 \%$ & $18.4 \%$ \\
\hline Italian dental students & $19.3 \%$ & $25.4 \%$ & $18.4 \%$ & $33.3 \%$ \\
\hline Lebanese dental students & $10.1 \%$ & $22.5 \%$ & $14 \%$ & $27 \%$ \\
\hline Lebanese biology students & $29.2 \%$ & $23.6 \%$ & $13.9 \%$ & $26.4 \%$ \\
\hline $\begin{array}{l}\text { Lebanese physical therapy } \\
\text { students }\end{array}$ & $26.9 \%$ & $30.8 \%$ & $21.2 \%$ & $46.2 \%$ \\
\hline
\end{tabular}

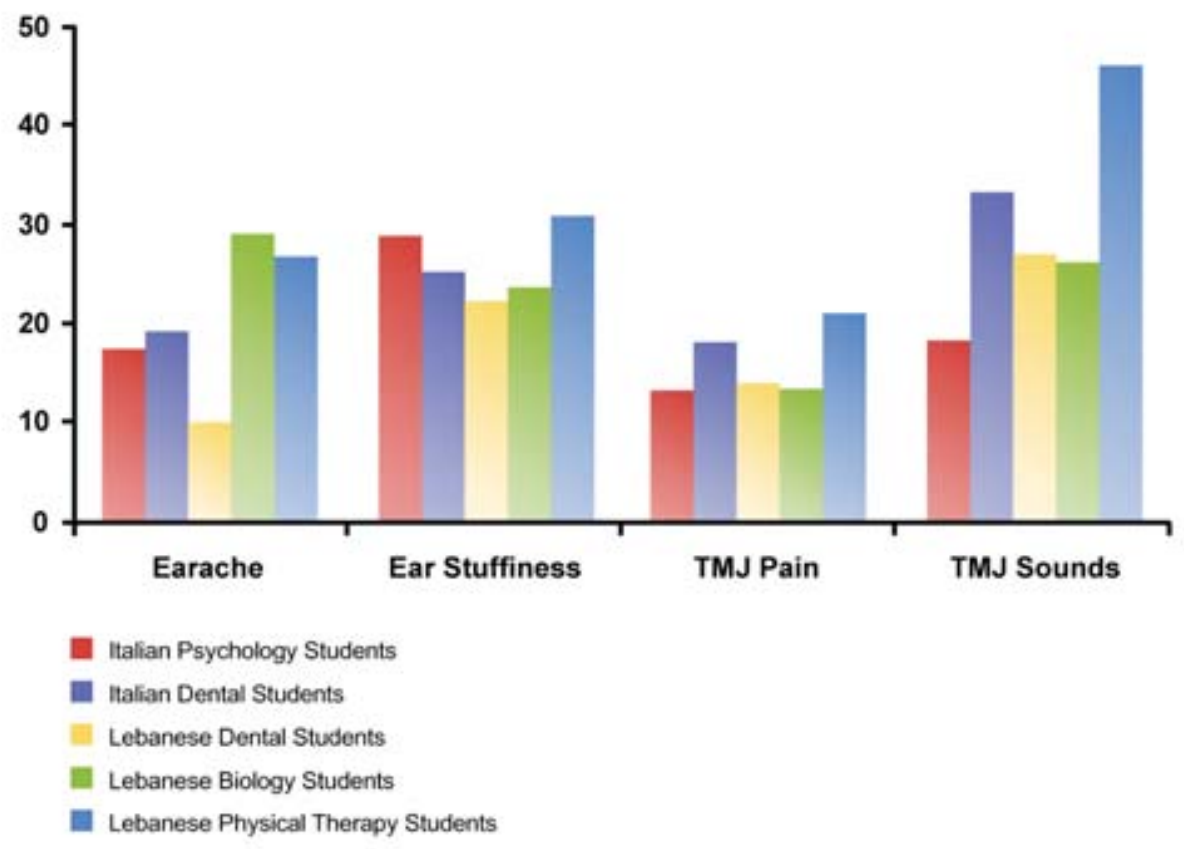

Figure 2. Prevalence of TMD symptoms in the selected sub-populations.

Table 2. Intensity of TMD symptoms in the selected sub-populations.

\begin{tabular}{|l|c|c|c|c|}
\hline & Earache & Ear Stuffiness & TMJ Pain & TMJ Sounds \\
\hline & Mean $( \pm$ SEM) & Mean $( \pm$ SEM) & Mean $( \pm$ SEM) & Mean $( \pm$ SEM $)$ \\
\hline Italian psychology students & $0.24( \pm 0.06)$ & $0.33( \pm 0.06)$ & $0.14( \pm 0.03)$ & $0.17( \pm 0.04)$ \\
\hline Italian dental students & $0.19( \pm 0.04)$ & $0.28( \pm 0.05)$ & $0.19( \pm 0.04)$ & $0.42( \pm 0.07)$ \\
\hline Lebanese dental students & $0.11( \pm 0.05)$ & $0.25( \pm 0.04)$ & $0.17( \pm 0.04)$ & $0.26( \pm 0.04)$ \\
\hline Lebanese biology students & $0.23( \pm 0.05)$ & $0.21( \pm 0.05)$ & $0.14( \pm 0.04)$ & $0.31( \pm 0.07)$ \\
\hline $\begin{array}{l}\text { Lebanese physical therapy } \\
\text { students }\end{array}$ & $0.34( \pm 0.09)$ & $0.39( \pm 0.09)$ & $0.26( \pm 0.09)$ & $0.58( \pm 0.12)$ \\
\hline p-value & $=0.038$ & $>0.1$ & $>0.1$ & $<0.001$ \\
\hline
\end{tabular}




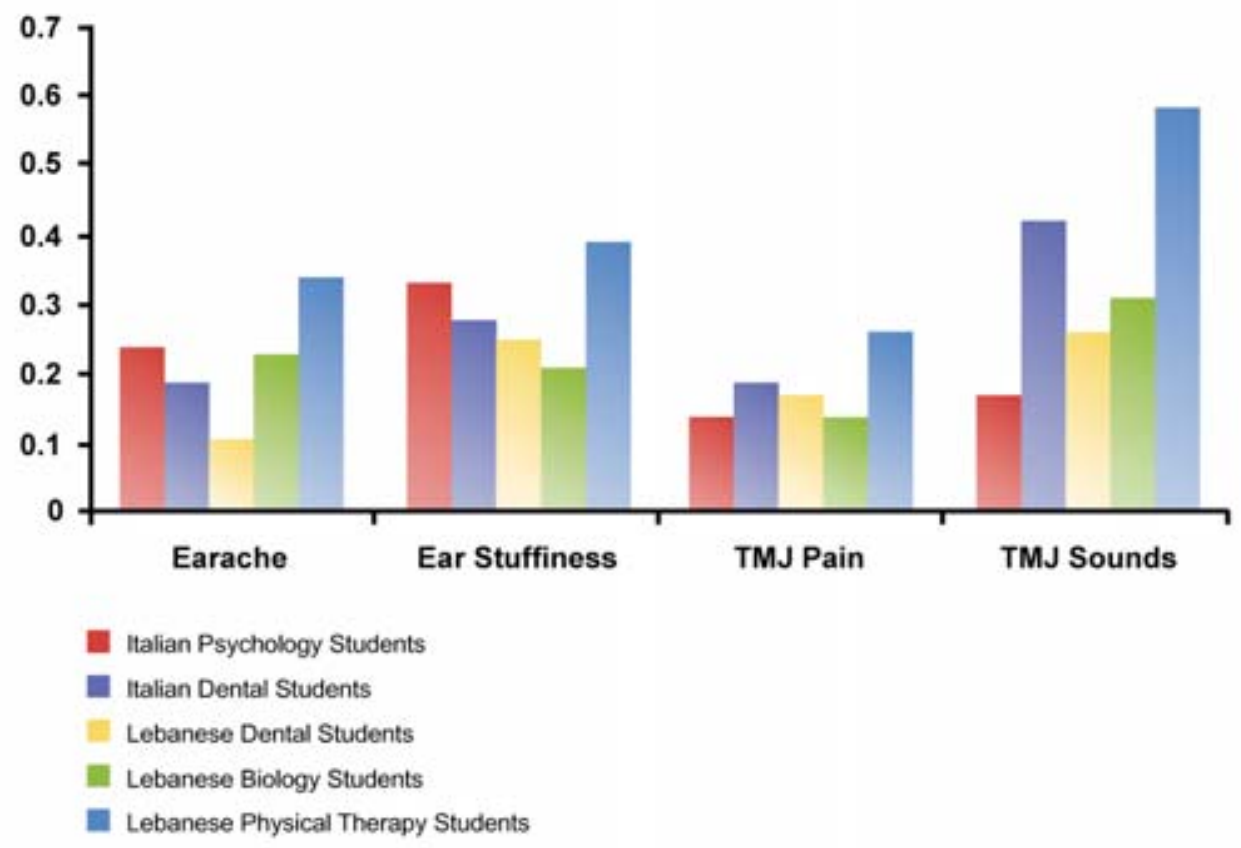

Figure 3. Intensity of TMD symptoms in the selected sub-populations.

Pair wise comparisons were conducted to evaluate significant differences between the groups for intensity of earache. The results showed only Lebanese dental students (mean = 0.11 ) were significantly different from Lebanese physical therapy students ( mean $=0.34$ ), $\mathrm{p}=0.039$.

When evaluating significant differences among the groups for intensity of TMJ sounds, the Italian psychology students (mean $=0.17$ ) were different from Italian dental students (mean $=0.42$ ) $\mathrm{p}=0.009$ and Lebanese physical therapy students (mean $=0.58), p<0.001$. Moreover, Lebanese dental students (mean $=0.26$ ) were diferent from Lebanese physical therapy students, $p=0.006$. No different scores were observed between the rest of the groups, $p>0.01$ (see Figure 3 ).

Pearson correlation was found to be significant when assessing intensity of TMJ pain and ipsilateral TMJ sounds in all the groups $(p<0.01)$ except for Lebanese biology students. Other correlations between the intensity of the symptoms were found in some of the subpopulations but were not consistent with the results in the other groups.

Pearson correlation was found to be significant $(P<0.01)$ for all symptoms except for left TMJ pain and right TMJ pain in Italian psychology students, when they were correlated with the same symptom on the other side. Correlations varied between low, medium, and high. The results are shown in Table 3.

\section{Discussion}

Comparing the selected sub-populations for different cultural background and education, we found different prevalence and intensity of some symptoms of TMD such as earache and TMJ sounds, but we could not detect any difference in the prevalence and intensity of ear stuffiness and TMJ pain.

Examining the statistical results it was evident the differences in the prevalence of the symptoms were due to the reports of the students belonging to certain sub-populations. In particular, Lebanese dental students were significantly different from Italian dental students. With regard to earache, Lebanese biology students differed from Lebanese physical therapy students and Italian psychology students were different from Italian dental students and Lebanese physical therapy students. Lebanese physical therapy students were different from Lebanese dental students and Lebanese biology students when evaluating TMJ sounds.

Also, examining the results for the intensity of the symptoms it was evident the statistical differences 
Table 3. Pearson correlation of intensity of earache, ear stuffiness, TMJ pain and TMJ sounds in the selected sub-populations.

\begin{tabular}{|c|c|c|c|c|c|}
\hline $\begin{array}{l}\text { Pearson } \\
\text { Correlation }\end{array}$ & $\begin{array}{l}\text { Lebanese Physical } \\
\text { Therapy Students }\end{array}$ & $\begin{array}{l}\text { Lebanese } \\
\text { Biology } \\
\text { Students }\end{array}$ & $\begin{array}{l}\text { Lebanese } \\
\text { Dental } \\
\text { Students }\end{array}$ & $\begin{array}{l}\text { Italian Dental } \\
\text { Students }\end{array}$ & $\begin{array}{l}\text { Italian } \\
\text { Psychology } \\
\text { Students }\end{array}$ \\
\hline $\begin{array}{l}\text { L earache/R } \\
\text { earache }\end{array}$ & $0.759^{* *}$ & $0.320^{* *}$ & $0.805^{* *}$ & $0.495^{* *}$ & $0.611^{*}$ \\
\hline $\begin{array}{l}\text { L ear stuffiness/R } \\
\text { ear stuffiness }\end{array}$ & $0.843^{* *}$ & $0.824^{* *}$ & $0.853^{* *}$ & $0.859^{\circ *}$ & $0.557^{* *}$ \\
\hline $\begin{array}{l}\text { LTMJ pain/R } \\
\text { TMJ pain }\end{array}$ & $0.835^{* *}$ & $0.941^{* *}$ & $0.698^{\circ *}$ & $0.649^{* *}$ & 0.167 \\
\hline $\begin{array}{l}\text { LTMJ sounds/R } \\
\text { TMJ sounds }\end{array}$ & $0.812^{* *}$ & $0.760^{* *}$ & $0.688^{\circ *}$ & $0.764^{\circ *}$ & $0.639^{* *}$ \\
\hline $\begin{array}{l}\text { L earache/L ear } \\
\text { stuffiness }\end{array}$ & $0.385^{* *}$ & -0.041 & $0.344^{* *}$ & $0.253^{* *}$ & 0.166 \\
\hline $\begin{array}{l}\text { Rearache/R ear } \\
\text { stuffiness }\end{array}$ & $0.406^{* *}$ & -0.123 & $0.410^{* *}$ & 0.084 & $0.308^{* *}$ \\
\hline $\begin{array}{l}\text { L earache/L TMJ } \\
\text { pain }\end{array}$ & 0.099 & 0.138 & $0.406^{\circ *}$ & 0.132 & $0.227^{*}$ \\
\hline $\begin{array}{l}\text { Rearache/R TMJ } \\
\text { pain }\end{array}$ & -0.094 & 0.088 & $0.278^{\circ *}$ & $0.378^{\circ *}$ & $0.247^{* *}$ \\
\hline $\begin{array}{l}\text { L earache/L TMJ } \\
\text { sounds }\end{array}$ & 0.130 & 0.057 & $0.219^{* *}$ & 0.104 & 0.136 \\
\hline $\begin{array}{l}\text { R earache/R TMJ } \\
\text { sounds }\end{array}$ & 0.173 & 0.147 & $0.255^{\circ *}$ & $0.355^{\circ *}$ & 0.112 \\
\hline $\begin{array}{l}\text { L ear stuffiness/L } \\
\text { TMJ pain }\end{array}$ & 0.000 & -0.003 & $0.201^{* *}$ & 0.146 & -0.013 \\
\hline $\begin{array}{l}\text { Rear stuffiness/ } \\
\text { RTMJ pain }\end{array}$ & -0.140 & -0.008 & 0.056 & 0.162 & $0.351^{* *}$ \\
\hline $\begin{array}{l}\text { L ear stuffiness } / \mathrm{L} \\
\text { TMJ sounds }\end{array}$ & $0.280^{\circ}$ & 0.107 & $0.148^{*}$ & $0.207^{*}$ & $0.293^{* *}$ \\
\hline $\begin{array}{l}\text { Rear stuffiness/ } \\
\text { R TMJ sounds }\end{array}$ & $0.400^{* *}$ & 0.100 & 0.146 & 0.108 & $0.369^{* *}$ \\
\hline $\begin{array}{l}\text { LTMJ pain/L } \\
\text { TMJ sounds }\end{array}$ & $0.514^{* *}$ & 0.159 & $0.231^{*}$ & $0.456^{\circ *}$ & $0.248^{\circ *}$ \\
\hline $\begin{array}{l}\text { RTMJ Pain/R } \\
\text { TMJ sounds }\end{array}$ & $0.812^{* *}$ & 0.222 & $0.389^{* *}$ & $0.555^{* *}$ & $0.258^{\circ *}$ \\
\hline
\end{tabular}

were due to the reports of the students belonging to certain sub-populations. In particular, Lebanese dental students were significantly different from Lebanese physical therapy students when evaluating earache. Italian psychology students were different from Italian dental students and Lebanese physical therapy students, and Lebanese dental students were different from Lebanese physical therapy students when evaluating TMJ sounds.
The current results are not consistent with differences in cultural background; in fact we could not find symptoms consistently more prevalent or intense in either the Italian or the Lebanese sub-populations. This seems to agree with a previous study by Nourallah and Johansson ${ }^{14}$ who reported a prevalence of signs and symptoms of TMD in a Saudi Arabian population comparable to the prevalence in western populations. 
On the other hand, the results are also not consistent with differences in education because both the highest prevalence and intensity of TMJ sounds were detected in Italian dental students and Lebanese physical therapy students and the lowest in Italian psychology students and Lebanese biology students. Therefore, dental studies do not seem to be consistently related to a particular risk for TMD.

Although statistical significance was not always reached, Lebanese physical therapy students constantly reported a higher intensity of all the symptoms assessed, and also a higher prevalence of almost all the symptoms (with the exception of earache). This might suggest some role of manual activity of physical therapy students in precipitating or perpetuating the symptomatology of TMD. Nonetheless, data are insufficient to draw definitive conclusions. Considering the group of Lebanese physical therapy students was the smallest in this survey, represented by only 52 subjects, this factor may have influenced the results.

Looking at the prevalence of each symptom separately our results show $10.1 \%$ to $29.2 \%$ of the subjects reported earache, $22.5 \%$ to $30.8 \%$ reported ear stuffiness, $13.2 \%$ to $21.2 \%$ reported TMJ pain, and $18.4 \%$ to $46.2 \%$ reported TMJ sounds.

Ear symptoms are frequent in patients with TMD with an overall prevalence of $59.9 \%$; $^{4}$ that seems higher than the prevalence of $10.1 \%$ to $30.8 \%$ found in the present study for earache and ear stuffiness. Unfortunately, in the study by Lam et al. ${ }^{4}$ the prevalence of each symptom was not reported, and we cannot reliably compare the results. Different results were shown by Gelb et al. ${ }^{15}$ who reported prevalence of tinnitus in $42 \%$ of the patients, otalgia in $35 \%$, dizziness in $18 \%$, and hearing loss in $14 \%$ of them and by Kuttila et al. ${ }^{16}$ who reported prevalence of tinnitus in $12 \%$ to $17 \%$ of the patients, otalgia in $12 \%$ to $16 \%$, and ear stuffiness in $5 \%$ to $9 \%$ of them.

The latter results are closer to the values we found for earache (otalgia), but are much lower than the values we found for ear stuffiness. However, some bias comes from the fact the sub-populations included in the present study cannot be considered neither patient nor nonpatient samples because clinical evaluation of the subjects was not required as a selection criterion. Therefore, patients and non-patients were probably both present in the groups.

Another factor requiring consideration is TMJ pain and TMJ sounds are typical and specific for TMD, but earache and ear stuffiness are not. Since we did not assess the subjects clinically, we do not know if these symptoms reported were an expression of TMD or ear pathology.

Prevalence of TMJ sounds reported by Elfving et al. ${ }^{12}$ was $56 \%$ in TMD patients and $36 \%$ in matched controls; Agerberg et al. ${ }^{13}$ found prevalence of $39 \%$ in the general population and $79 \%$ in previous patients. With the limitations due to the potentially mixed (patients and nonpatients) composition of the groups of the present study, the percentages are comparable although the range detected is very wide $(18.4 \%$ to $46.2 \%)$.

Examining the correlation between different symptoms, the most relevant result was achieved when assessing intensity of TMJ pain and ipsilateral TMJ sounds; such association was present in all the groups $(p<0.01)$ except for the Lebanese biology students. This information might suggest the occurrence of one of these symptoms is related to the other. Although the variable "time" was not evaluated in the present study and we cannot state the presence of TMJ sounds is a predictor of the development of TMJ pain based on these results, it might make sense biologically. Most of the time TMJ noises are due either to osteoarthrosis of the TMJ (crepitation) or to disc displacement with reduction of the TMJ (clicks). The two conditions represent pathologies altering the regular smooth movement of the condyle and the disc during mouth opening and closing and, therefore, predispose the joint to inflammation and, consequently, joint pain. Nonetheless, clinical practice experience suggests many cases of patients with TMJ noises remain "pain-free" forever and never develop a painful symptomatology. Still the correlation mentioned above needs to be kept in mind. In addition, considering the results of a fouryear yearly follow-up of Japanese young girls performed by Kitai et al.," ${ }^{17}$ showed the subjects 
who exhibited TMJ noises during at least one of the surveys of the four-year survey period reported a significantly higher prevalence of pain than those who did not exhibit TMJ noises.

Another significant correlation was found in all symptoms except for left TMJ pain and right TMJ pain in Italian psychology students, when they were correlated with the same symptom on the contralateral side suggesting most of the symptoms are bilateral. Clarifying again the variable "time" was not evaluated in the present study and, therefore, no cause-and-effect can be inferred. Such information might be useful before any treatment is started in order to anticipate the occurrence of the same symptom on the other side. The reason is probably due to the fact the movements of the mandible with respect to the skull are dependent on the two TMJs. These two joints are connected by the mandible that is one bone, therefore, all the movements occurring in one TMJ are necessarily transmitted to the contralateral joint. If dysfunction affects one of the joints, mandibular movements are going to be affected and, in turn, the contralateral TMJ is going to be affected as well with possible additional risk of developing pain and dysfunction.

\section{Conclusions}

Based on findings of

the study there is a

lack of a significant

difference in the

prevalence and intensity

of ear stuffiness and

TMJ pain in sub-

populations differing

by cultural background

and education. On the

other hand, some differences could be found in the prevalence and intensity of earache and TMJ sounds, although correlation with cultural background and education are difficult to establish.

Moreover, association between TMJ sounds and TMJ pain can be detected in selected sub-populations, and correlation between one symptom on one side with the same symptom on the contralateral side were noted suggesting most of these symptoms are bilateral. Such information might be useful before any treatment is started in order to anticipate the possible occurrence of associated symptoms or the same symptom on the other side.

\section{References}

1. Okeson JP, ed. Orofacial pain. Guidelines for assessment, diagnosis, and management. Chicago : Quintessence Publishing Co, Inc; 1996:116-117.

2. Carlsson GE. Epidemiology and treatment need for temporomandibular disorders. J Orofac Pain 1999;13: 232-237.

3. Tuz HH, Onder EM, Kisnisci RS. Prevalence of otologic complaints in patients with temporomandibular disorder. Am J Orthod Dentofacial Orthop;2003 123: 620-623.

4. Lam DK, Lawrence HP, Tenembaum HC. Aural symptoms in temporomandibular disorder patients attending a craniofacial pain unit. J Orofac Pain 2001;15: 146-157.

5. Parker WS, Chole RA. Tinnitus, vertigo, and temporomandibular disorders. Am J Orthod Dentofac Orthop 1995;107: 153-158.

6. Ren YF, Isberg A. Tinnitus in patients with temporomandibular joint internal derangement. J Craniomandib Pract 1995;13: 75-80.

7. Cooper BC, Cooper DL. Recognizing otolaryngologic symptoms in patients with temporomandibular disorders. J Craniomandib Pract 1993;11: 260-267.

8. Rubinstein B. Tinnitus and craniomandibular disorders: is there a link? Swed Dent J Suppl 1993;95: $1-46$.

9. Rubinstein B, Axelsson A, Carlsson GE. Prevalence of signs and symptoms of craniomandibular disorders in tinnitus patients. J Craniomandib Disord 1990;4: 186-192.

10. Jagger RG, Wood C. Signs and symptoms of temporomandibular joint dysfunction in a Saudi Arabian population. J Oral Rehabil 1992;19:353-359.

11. Agerberg G, Inkapool I. Craniomandibular disorders in an urban Swedish population. J Craniomandib Disord 1990;4: 154-164. 
12. Elfving L, Helkimo M, Magnusson T. Prevalence of different temporomandibular joint sounds, with emphasis on disc-displacement, in patients with temporomandibular disorders and controls. Swed Dent J 2002;26: 9-19.

13. Agerberg G, Carlsson GE. Symptoms of functional disturbances of the masticatory system. A comparison of frequencies in a population sample and in a group of patients. Acta Odontol Scand 1975;33: 183-190.

14. Nourallah $\mathrm{H}$, Johansson A. Prevalence of signs and symptoms of temporomandibular disorders in a young male Saudi population. J Oral Rehabil 1995;22: 343-347.

15. Gelb H, Calderone JP, Gross SM, Kantor ME. The role of the dentist and the otolaryngologist in evaluating temporomandibular joint syndromes. J Prosthet Dent 1967;18: 497-503.

16. Kuttila S, Kuttila M, Le Bell Y, Alanen P, Jouko S. Aural symptoms and signs of temporomandibular disorders in association with treatment need and visits to a physician. Laryngoscope 1999;109: 1669-1673.

17. Kitai N, Takada K, Yasuda Y, Verdonck A, Carels C. Pain and other cardinal TMJ dysfunction symptoms: a longitudinal survey of Japanese female adolescents. J Oral Rehabil 1997;24: 741-748.

\section{About the Authors}

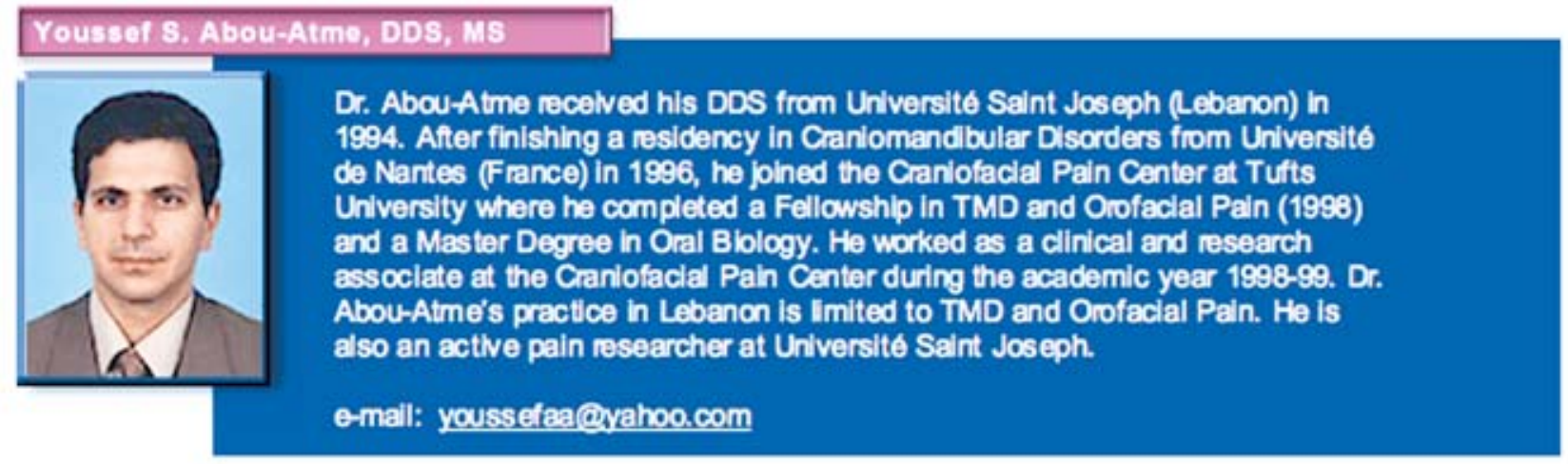

\section{Khalld H. Zawawl, BDS, DSc}

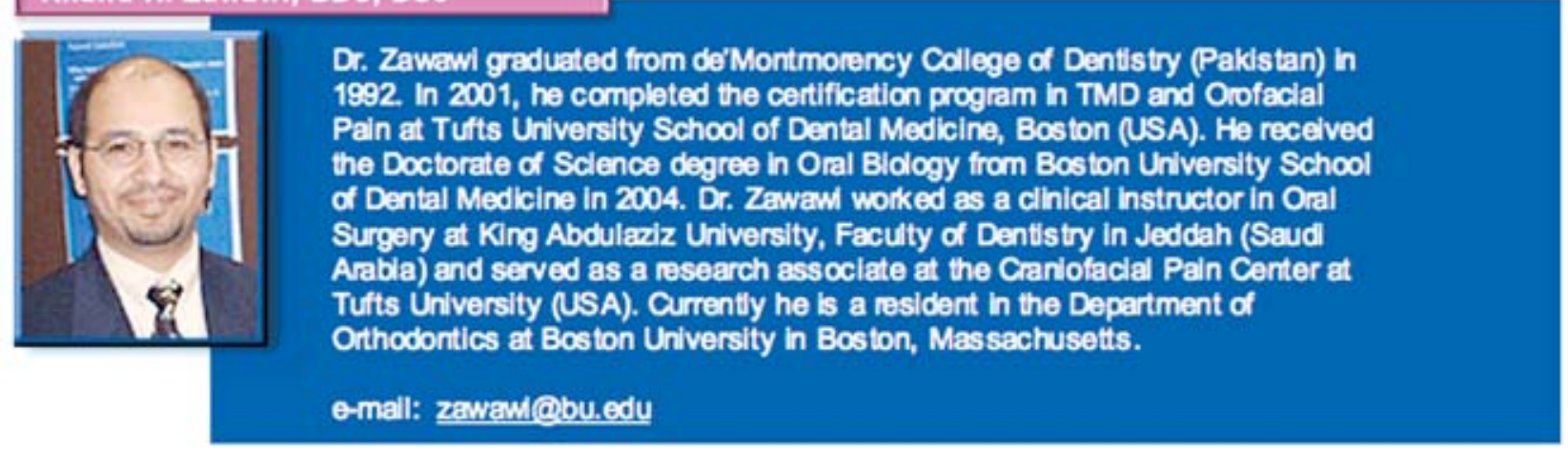

\section{Marcello Molls, DMD, RPharm}

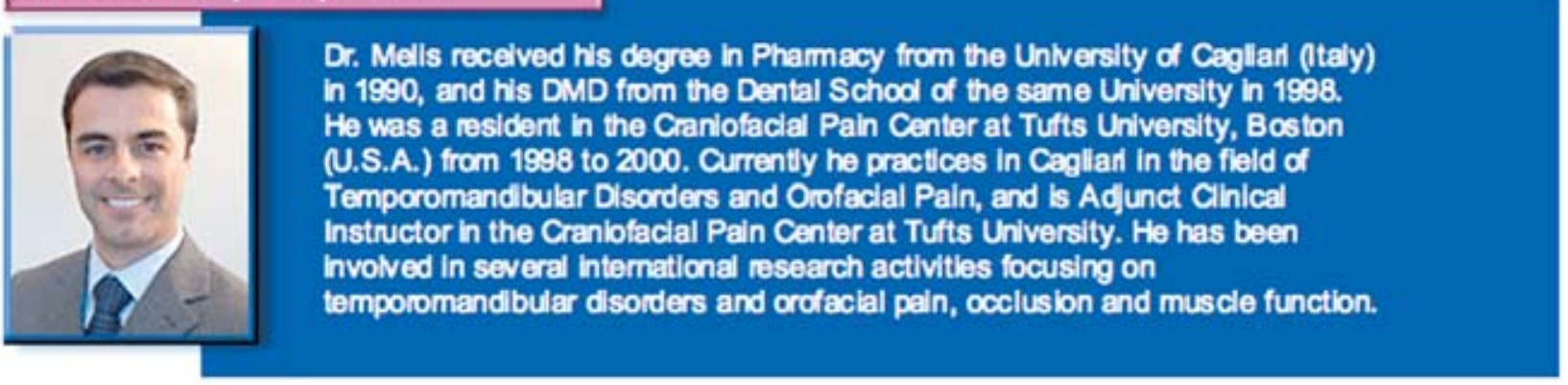

